\title{
METHOD DEVELOPMENT AND VALIDATION FOR THE ESTIMATION OF ENTECAVIR IN BULK AND PHARMACEUTICAL DOSAGE FORMS BY RP-HPLC
}

\author{
SWATHI P. ${ }^{*}$, S. VIDYADHARA ${ }^{2}$, R. L. C. SASIDHAR ${ }^{3}$, K. KALYAN CHAKRAVARTHI ${ }^{4}$ \\ 1, 4NRK and KSR Gupta College of Pharmacy, Tenali, Andhra Pradesh, ${ }^{2,3}$ Chebrolu Hanumaiah Institute of Pharmaceutical Sciences, Guntur, \\ Andhra Pradesh \\ Email: swathipamidimarri@gmail.com
}

Received: 24 May 2017, Revised and Accepted: 22 Jul 2017

\begin{abstract}
Objective: The objective and purpose of the analysis have sensibly assessed by selecting of a rapid and sensitive RP-HPLC method for Entecavir in bulk and pharmaceutical dosage form by using the most commonly employed C-18column with UV detection.

Methods: In estimation by RP-HPLC method Agilent 1120 compact LC system with variable programmable UV detector and Rheodyne injector with $20 \mu \mathrm{l}$ fixed loop was used for the chromatographic separation. The mode of operation was isocratic with the components of a solution consisting of methanol: acetonitrile(70:30v/v) and triethanolamine (2-4drops)at the flow rate of $1.2 \mathrm{ml} / \mathrm{min}$ and run time was 10 min. Forced degradation studies were conducted to evaluate the stability and specificity of the method along with the validation parameters.
\end{abstract}

Results: Validation parameters of HPLC were found at a detection wavelength of $255 \mathrm{~nm}$. Linearity was observed with the concentration range (Beer's law range) $20-100 \mu \mathrm{g} / \mathrm{ml}$ with $\mathrm{R}^{2}=0.9991$. Robustness with detection wavelengths 253 and $257 \mathrm{~nm}$ with a flow rate of $1 \mathrm{ml} / \mathrm{min}$ and 1.4 $\mathrm{ml} / \mathrm{min}$ showed good results. The retention time of the drug was $2.64 \mathrm{~min}$ and assay showed $98.1 \%$.

Conclusion: The proposed RP-HPLC method was validated as per the ICH Q2B Guidelines, and was found to be applicable for routine quantitative analysis of Entecavir by RP-HPLC using UV detector in pharmaceutical dosage forms. The results of linearity, precision, accuracy and specificity, were proved, that does not exceed certain specified limits. The method provides selective quantification with no interference from other formulation excipients. The proposed method was highly sensitive, reproducible, reliable, robust and specific. Therefore, this method is a simple, rapid analysis may actually be more desirable than a more complicated and time-consuming process. The degradation studies at various stress conditions like thermal and hydrolytic, drug gets degraded at a temperature of $80^{\circ} \mathrm{C}$ and refluxing with water at $70{ }^{\circ} \mathrm{C}$ for $24 \mathrm{hours}$.

Keywords: RP-HPLC, Entecavir, Validation, Forced degradation

(C) 2017 The Authors. Published by Innovare Academic Sciences Pvt Ltd. This is an open access article under the CC BY license (http://creativecommons.org/licenses/by/4.0/) DOI: http://dx.doi.org/10.22159/ijcpr.2017v9i5.22151

\section{INTRODUCTION}

Entecavir is an Antiretroviral agent. It is a guanosine nucleoside analogue with selective activity against HBV (Hepatitis B Virus) and HIV.(Human Immunodeficiency Virus)[1]. It is chemically 2-Amino1,9-dihydro-9-[(1S,3R,4S)-4-hydroxy-3-(hydroxymethyl)-2methylenecyclopentyl]-6H-purin-6-one and it is an orally administered antiviral drug, $0.5 \mathrm{mg}$ once daily [2, 3].

The drug is white to off white powder having the molecular formula $\mathrm{C}_{12} \mathrm{H}_{15} \mathrm{~N}_{5} \mathrm{O}_{3}$, and molecular weight 277.28. The PKa values strongest acidic-8strongestbasic- 2.77<smiles>C=C1[C@H](CO)C(O)C[C@H]1n1cnc2c(=O)[nH]c(N)nc21</smiles>

\section{Molecular structure of entecavir}

Among the other nucleoside analogues, [4, 5] Entecavir (Baraclude) is a novel guanine nucleoside analogue that inhibits HBV, DNA polymerase at both the priming and elongation steps required for viral replication and the excellent in Vitro potency and resistance profile of Entecavir addresses unmet medical needs. The most common adverse effects of Entecavir have been headache, fatigue, dizziness, nausea and vomiting. According to the literature survey, it was found that few analytical methods on UV Spectrophotometer [6, 7] RP-HPLC and Stability Indicating Studies were reported for Entecavir where the method was carried out by using potassium phosphate buffer $[8,9]$ with the mobile phases. Simultaneous determination $[10,11]$ and quantitative analysis were performed with LC-MS in human plasma $[12,13]$. Novel spectrophotometric methods have been developed for the estimation of Entecavir [14] Hence there is need to develop and validate a new analytical method to estimate Entecavir with Forced degradable studies.

The aim is to develop simple, precise and accurate RP-HPLC method for the estimation of Entecavir in bulk and pharmaceutical dosage forms and the developed method can be validated according to the ICH guidelines.

\section{MATERIALS AND METHODS}

\section{Chemicals and reagents}

Standard drug Entecavir was procured from Mylan Laboratories, Hyderabad (gift sample). The marketed formulation was Baraclude, Entavir (Mylan Laboratories, Hyderabad) each tablet contains, Entecavir- $0.5 \mathrm{mg}, 1 \mathrm{mg}$. Methanol, acetonitrile and triethanolamine of HPLC grade were used.

\section{Instrumentation}

Axis AGN204-POelectronic balance, Ultra-sonic bath sonicator, Agilent 1120 compact LC system, with variable wavelength programmable UV detector and Rheodyne injector with $20 \mu$ fixed loop was used for the chromatographic separation. Ezchrome 
software was used for data analysis. Chromatographic separation was carried out on a $\mathrm{C}_{18}$ column (Agilent $\mathrm{T}_{\mathrm{c}}-\mathrm{c}-18(2) 5 \mu \mathrm{m}, 4.6 \times 250$ $\mathrm{mm}$ ) with the $\lambda \max 255 \mathrm{~nm}$.

\section{Selection of mobile phase}

The pure drug of Entecavir was injected into the isocratic HPLC system and run at different solvent systems. Different mobile phases like methanol with buffer PH-4, methanol with buffer PH-7, methanol and acetonitrile (50:50,70:30),methanol, acetonitrile and triethanolamine were tried in order to find the best conditions for the elution of Entecavir. It was found that methanol, acetonitrile, triethanolamine give satisfactory results as compared to other mobile phases. The mobile phase system was tried with different proportions and using different flow rates. Finally, the optimal composition of the mobile phase was determined to be methanol: acetonitrile $(70: 30 \mathrm{v} / \mathrm{v})$ and $2-4$ drops of triethanolamine at a flow rate of $1.2 \mathrm{ml} / \mathrm{min}$.

\section{Method development}

\section{Preparation of mobile phase}

The volume of HPLC grade methanol, acetonitrile (70:30v/v) and 24 drops of triethanolamine were mixed, filtered through a $0.45 \mu$ membrane filter and sonicated for $20 \mathrm{~min}$.

\section{Preparation of standard stock solution}

Accurately weigh and transfer $25 \mathrm{mg}$ of pure drug in a $25 \mathrm{ml}$ volumetric flask, and dissolved in $10 \mathrm{ml}$ of solvent, then the volume was made up to the mark with a solvent system to obtain a final concentration of $1000 \mu \mathrm{g} / \mathrm{ml}$. Filtered through a $0.45 \mu$ membrane filter and sonicated for $20 \mathrm{~min}$.

Degradation studies in solution were carried out at a drug concentration of $40 \mu \mathrm{g} / \mathrm{ml}$. (From the stock solution $0.4 \mathrm{ml}$ was pipetted out and transferred into $10 \mathrm{ml}$ volumetric flask and volume were made up to the mark with mobile phase.

\section{Selection of analytical concentration range}

Appropriate aliquots were pipetted out from the working stock solution $(1000 \mu \mathrm{g} / \mathrm{ml})$ into a series of $10 \mathrm{ml}$ volumetric flasks. The volume was made up to the mark with the mobile phase to get a set of solutions having the concentration range, ranging from $20,40,60,80,100 \mu \mathrm{g} / \mathrm{ml}$. Triplicate dilutions of each of the above concentrations were prepared separately and from these triplicate solutions, $20 \mu \mathrm{l}$ of each concentration of the drug was injected into the HPLC system and their chromatograms were recorded under the described chromatographic conditions. A calibration curve of concentration vs. peak area was established. Regression equations were established and the correlation coefficients were determined.

\section{Preparation of sample stock solution}

Marketed tablet formulation (Entavir) containing $0.5 \mathrm{mg}$ of Entecavir was analyzed by this method. Twenty tablets were accurately weighed and their average weight determined. The tablets were then crushed to fine powder and powder equivalent to $25 \mathrm{mg}$ was taken in $25 \mathrm{ml}$ volumetric flask and dissolved in $25 \mathrm{ml}$ of mobile phase. The solution was kept for sonication $15 \mathrm{~min}$. The solution was made up to the mark with the mobile phase and filtered through $0.45 \mu$ membrane filter to get the concentration of $1000 \mu \mathrm{g} / \mathrm{ml}$.

\section{System suitability}

The criteria selected was based on the actual performance of the method as determined during its validation. This is to ensure that the method can generate results of acceptable accuracy and precision. System suitability was performed prior to analysis as per the USP (2000). The chromatogram of system suitability was shown in fig. 1.

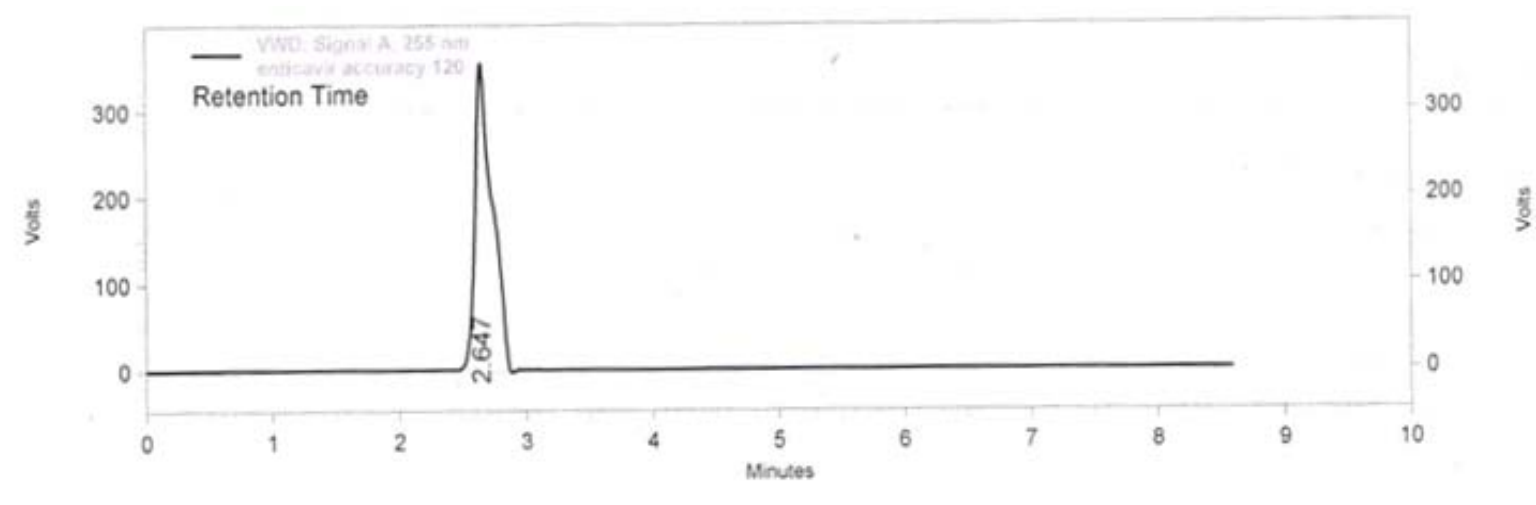

Fig. 1: Chromatogram of system suitability

Validation data of system suitability

Table 1: Data showing system suitability

\begin{tabular}{lll}
\hline S. No. & Parameters & Results \\
\hline 1 & No. of theoretical plates & 12182 \\
2 & Tailing factor & 1.3 \\
3 & Retention time & $2.6-2.68$ \\
4 & \%RSD & 0.4 \\
\hline
\end{tabular}

Following Analytical validation parameters (2) were performed

\section{Linearity}

Linearity was determined by taking the concentrations of 20,40 , 60,80 and $100 \mu \mathrm{g} / \mathrm{ml}$ from the standard stock solution. A calibration curve was plotted by taking peak area vs concentration.

The slope, intercept and regression were showed in the fig. 2 . 


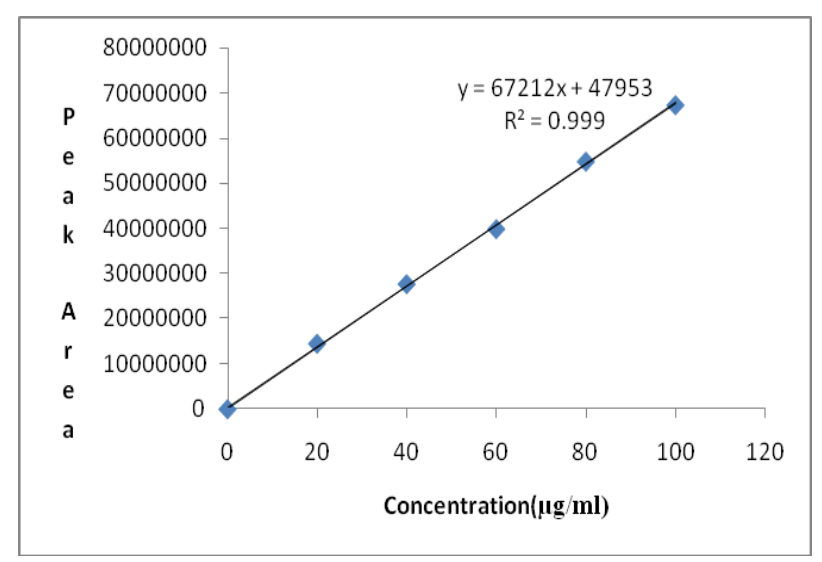

Fig. 2: Calibration curve of entecavir by RP-HPLC $\left(\lambda_{\max }-255 \mathrm{~nm}\right)$

Limit of detection (LOD) and limit of quantification (LOQ) were manually calculated from the slope of the calibration curve and standard deviation using the following equation (1) as per ICH guidelines.

$$
\text { LOD }=\frac{3.3}{S} \sigma \text { and LOQ }=\frac{10}{S} \sigma
$$

Where $\sigma$ is mean of standard deviation and $S$ is the slope of the calibration curve.

\section{Accuracy}

The accuracy of the proposed method was determined by standard addition method, by adding a known amount of standard solution of pure drug to a pre-analyzed sample solution, at three recovery levels $80 \%, 100 \%, 120 \%$ of the label claim. The percent recovery level was shown in table 2 .

\section{Precision}

The precision of an analytical procedure was performed by a series of measurements obtained from multiple sampling of the same homogenous sample under the prescribed conditions. The data regarding intra-day and inter-day precision with \%RSD values were given in table 3.

\section{Ruggedness}

Variations of working solutions were given by the co-analyst and the peak areas were recorded and the \%RSD was calculated statistically. The results of ruggedness were given in table 6 .

Table 2: Statistical validation data of accuracy

\begin{tabular}{llll}
\hline $\begin{array}{l}\text { Recovery } \\
\text { level (\%) }\end{array}$ & Amount added $(\boldsymbol{\mu g} / \mathbf{m l})$ & Amount found $(\boldsymbol{\mu g} / \mathbf{m l})$ \\
\cline { 2 - 3 } & standard & Test & \\
\hline 80 & 0.4 & 0.4 & 0.48 \\
100 & 0.6 & 0.4 & 0.495 \\
120 & 0.8 & 0.4 & 0.49 \\
Mean recovery & $96 \%-99 \%$ & & $96.1 \%$ \\
\hline
\end{tabular}

Table 3: Statistical validation data of intra and inter day precision

\begin{tabular}{lllll}
\hline Parameters & Precision & & & \\
\cline { 2 - 4 } & Intra-day & Inter-day & Day 3 \\
\cline { 2 - 4 } & & Day 1 & 456250 & 573044.3 \\
S. D & 301631.2 & 323701.3 & 68721737 \\
Mean & 68513363 & 68573769 & 6858236 & 0.83 \\
\%RSD & 0.4 & 0.47 & 0.66 & \\
\hline
\end{tabular}

\section{Robustness}

Table 4: Robustness data showing variation in detection wave length

\begin{tabular}{|c|c|c|c|c|c|}
\hline Wave length (nm) & Retention time $\left(\mathrm{R}_{\mathrm{t}}\right)$ & Peak area & Standard deviation & Mean & \%RSD \\
\hline \multirow[t]{3}{*}{253} & 2.647 & 70809564 & 483570.7 & 78570247 & 0.6154 \\
\hline & 2.64 & 70743692 & & & \\
\hline & 2.62 & 70023874 & & & \\
\hline 257 & 2.647 & 60311488 & 366568.9 & 78527537 & 0.466 \\
\hline
\end{tabular}

Small changes in the operational conditions were allowed and the extent to which the method was robust was estimated. Deviations of $\pm 2 \mathrm{~nm}$ in the detection wavelength and $\pm 0.1 \mathrm{ml} / \mathrm{min}$ in the flow rate were tried individually. The data regarding wavelength and flow rate were shown in table 4,5 .

Table 5: Robustness data showing variation in flow rate

\begin{tabular}{|c|c|c|c|c|c|}
\hline $\begin{array}{l}\text { Flow rate } \\
\text { (ml/min) }\end{array}$ & Retention time $\left(R_{t}\right)$ & Peak area & SD & Mean & \%RSD \\
\hline 1 & $\begin{array}{l}2.643 \\
2.64 \\
2.64\end{array}$ & $\begin{array}{l}68598291 \\
68598045 \\
68459823\end{array}$ & 79873.62 & 68552053 & 0.11 \\
\hline 1.4 & $\begin{array}{l}2.267 \\
2.26 \\
2.23\end{array}$ & $\begin{array}{l}68694526 \\
68694526 \\
68984682\end{array}$ & 167521.6 & 68791244 & 0.24 \\
\hline
\end{tabular}


Table 6: Results of ruggedness

\begin{tabular}{lll}
\hline Concentration $(\boldsymbol{\mu g} / \mathbf{m l})$ & Peak area \\
\cline { 2 - 3 } & Analyst1 & Analyst2 \\
\hline 100 & 68353829 & 68125439 \\
100 & 68453672 & 68754938 \\
100 & 68594320 & 68253784 \\
100 & 68164782 & 68569432 \\
100 & 68493872 & 68243479 \\
100 & 68374619 & 329626 \\
S. D & 238518.1 & 68483909 \\
Mean & 68489182.3 & 0.48 \\
\hline
\end{tabular}

\section{Assay}

\section{Analysis of tablet formulation}

Marketed tablet formulation (Entaliv) containing $0.5 \mathrm{mg}$ of Entecavir was analyzed by this method. Twenty tablets were accurately weighed and average weight was determined. The tablets were crushed into fine powder and a powder equivalent to $25 \mathrm{mg}$ of pure drug was weighed and transferred into $25 \mathrm{ml}$ volumetric flask, dissolved in $25 \mathrm{ml}$ of the solvent system and sonicated for $20 \mathrm{~min}$. The solution was filtered through whatmann filter paper. The residue was washed with $10 \mathrm{ml}$ portions of solvent system three times and the total volume of the filtrate was made up to the mark solvent system to obtain $1000 \mu \mathrm{g} / \mathrm{ml}\left(1^{\circ}\right.$ stock solution).

From the $1^{\circ}$ stock solution, $1.0 \mathrm{ml}$ was pipetted out and transferred into a $10 \mathrm{ml}$ volumetric flask and the volume was made up to the mark with a solvent system to obtain the final concentration of $100 \mu \mathrm{g} / \mathrm{ml}$. Three replicates of above concentration were prepared and the absorbances were analyzed at $255 \mathrm{~nm}$. Then the concentration of the above solution was determined by substituting the absorbance value in regression equation method and the percentage purity was determined. The results of the marketed formulation were given in table 7 .

\section{Stability studies}

Forced degradation studies were conducted to evaluate the stability and specificity of the method [15].

\section{Forced degradation studies}

Forced degradation studies in solution were carried out at a drug concentration of $40 \mu \mathrm{g} / \mathrm{ml}$ from the standard stock solution.

\section{Thermal degradation}

In accordance to Arrhenius kinetics increasing temperature increases the rate of any degradation process. Thermal degradation studies were observed for 12 and $24 \mathrm{~h}$. There was a significant change in the peak and was shown in the fig. 3.

Table 7: Results of marketed formulation

\begin{tabular}{llll}
\hline Brand name & Lable claim & Amount recovered & \%Amount found \\
\hline Entavir & $0.5 \mathrm{mg}$ & $0.49 \mathrm{mg}$ & 98.1 \\
\hline
\end{tabular}

\section{Hydrolytic degradation}

The hydrolytic degradation was performed at a temperature of about $70{ }^{\circ} \mathrm{C}$ with a reflux condenser installed to avoid the loss of evaporation.
Reflux using water for stress testing with or without co-solvent at 70 ${ }^{\circ} \mathrm{C}$ for $2,4,6,8,12$ and 24 hours. The drug was not stable for $24 \mathrm{~h}$ and was observed by the chromatogram as shown in fig. 4 .

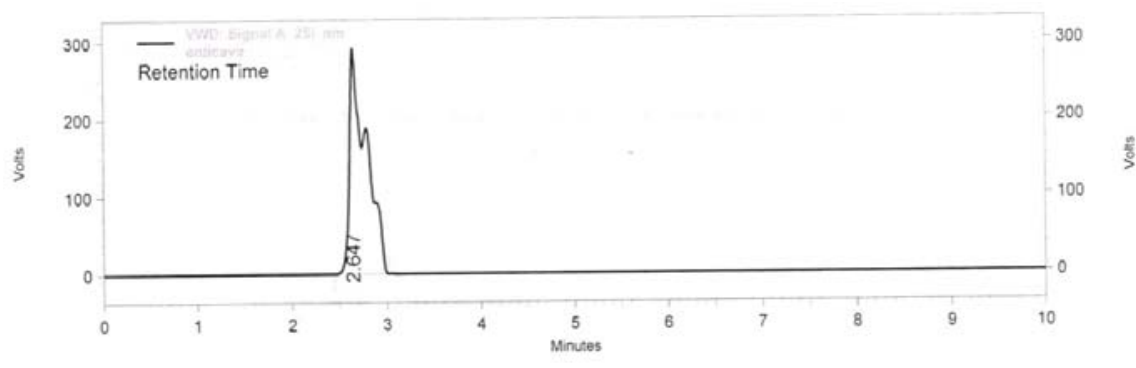

Fig. 3: Chromatogram of thermal degradation

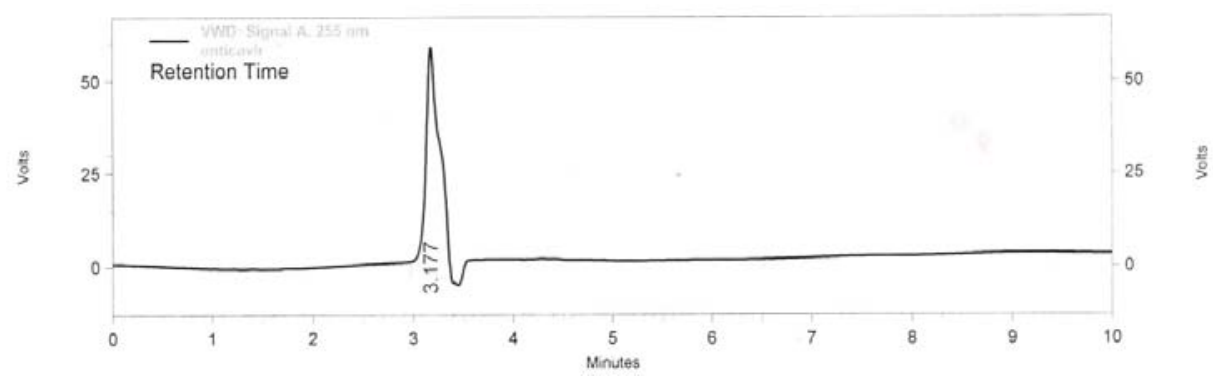

Fig. 4: Chromatogram of hydrolytic degradation 


\section{RESULTS AND DISCUSSION}

The developed RP-HPLC method for the estimation of Entecavir was validated as per ICH (Q2 B) guidelines. The method validation was done to ensure that the performance characteristics of the method meet the requirements of the intended analytical application. Initially, various mobile phase compositions were tried to elute the drug. Mobile phase ratio and flow rate were selected based on peak parameters (height, capacity, theoretical plates, tailing or symmetry factor), run time and resolution. The system with methanol: acetonitrile (70: $30 \mathrm{v} / \mathrm{v}$ ) and 2-4 drops of triethanolamine and $1.2 \mathrm{ml} / \mathrm{min}$ flow rate was selected.

The retention time for Entecavir was found to be $2.6 \mathrm{~min}$. The low \% RSD values $₫ 2$ ) indicated that the method was precise and accurate. Specificity of the chromatographic method was tested by injecting sample concentration prepared from the marketed formulation. The response was compared with that obtained from the standard drug. The chromatogram confirms the presence of Entecavir at $2.6 \mathrm{~min}$ without any interference.

The proposed method was validated in accordance with ICH parameters and was applied for analysis of the same in marketed formulations. The content of each component in the formulation was estimated by comparing the peak area of the test sample with that of the peak area of the standard and the results were found to be $98.1 \%$.

Entecavir was subjected to forced degradation studies; drug gets degraded at a temperature of $80^{\circ} \mathrm{C}$ and refluxing with water at $70^{\circ} \mathrm{C}$ for 24 hours. So care should be taken while storing the formulation as well as pure form.

\section{CONCLUSION}

When compared to other validation methods, the mobile phase used in this proposed method gives more life to the column and less usage of mobile phase because, according to the literature survey the mobile phase\{potassium phosphate buffer, acetonitrile (94:6)were used. There is a disadvantage of potassium phosphate buffer systems include the insolubility of phosphate salts and phosphates, will support the microbial growth which damages the column. The retention time obtained in this method was2.6 min while for the other methods the Rt is about 4-9 min. The less retention times gives short analysis time for the validation of Entecavir.

It was found to be an accurate method for a certain determination it may require expensive reagents, and in the interest of economy, it may be necessary to choose a method which yields results of sufficient accuracy in a reasonable time. Therefore, this method can be employed in quality control to estimate the amount of Entecavir in bulk and in pharmaceutical dosage forms.

\section{CONFLICT OF INTERESTS}

Declare none

\section{REFERENCES}

1. www.druginfosys.com. [Last accessed on 10 Apr 2017]
2. www.drugbank.ca/drugs/DB00709. [Last accessed on $10 \mathrm{Apr}$ 2017].

3. Dimou E, Papadimitropoulos V, Hadziyannis SJ. The role of entecavir in the treatment of chronic hepatitis B. Ther Clin Risk Management 2007;3:1077-86.

4. Ching Lung Lai, Man-Fung Yuen. The saga of Entecavir. Hepatol Int 2009;3:421-24.

5. Lai CL, Rosmawati M, Lao J, Van Vlierberghe H, Anderson $\mathrm{FH}$, Thomas $\mathrm{N}$, et al. Entecavir is superior to lamivudine in reducing hepatitis $\mathrm{B}$ virus DNA in patients with chronic hepatitis B infection. Gastroenterology 2002;123:1831-8.

6. Kiran Kumar V, Raju NA. Spectrophotometric estimation of Entecavir in pharmaceutical dosage formulations. Biomed Pharmacol J 2008;1. http://biomedpharmajournal.org/? $p=477$

7. SM Malipatil, Bharath S, Athanikar, Mogal dipali. UVspectrophotometric estimation of entecavir in tablet dosage form. Pharma Sci Monitoran Int J Pharm Sci 2012;3:56-67.

8. Dalmora SL, Sangoi Mda S, Nogueira DR, Da Silva LM. Validation of a stability-indicating RP-HPLC method for the determination of entecavir in tablet dosage form. J AOAC Int 2010;93:523-30.

9. Vijay Amirtharaj R, Vinay Kumar $\mathrm{Ch}, \mathrm{N}$ Senthil Kumar. Development and validation of RP-HPLC for the estimation of entecavir in tablet dosage form. Int J Res Pharm Biomed Sci 2011;2:1033-40.

10. Delepee R, Got L, Causse X, Agrofoglio LA, Si Ahmed SN. Simultaneous determination of tenofovir, adefovir, lamivudine, entecavir in plasma. Poster No.576. 05A. viral hepatitis-a) Hepatitis b)-Experimental; 2010. p. s215.

11. Jung BH, Naser L, Rezk, Bridges AS, Corbett AH, Angela D. Simultaneous determination of 17 antiretroviral drugs in human plasma for quantitative analysis with liquid chromatography-tandem mass spectrometry. Biomed Chromatogr 2007;21:1095-104.

12. Duxi Zhang, Yunlin Fu, Jane P Gale, Anne F Aubry, Mark E Arnold. A sensitive method for the determination of entecavir at picogram per millilitre level in human plasma by solid phase extraction and high-pH LC-MS/MS. J Pharm Biomed Anal 2009;49:1027-33.

13. Denny Yifei Liu, Erika Hess. Determination of entecavir in human plasma using Lc/Ms/Ms. Tandem Labs; 2010.

14. Rajeswari P Subrahmanyam, G Devala Rao, G Sudhakar Sai Babu. Novel spectrophotometric methods for the determination of entecavir in pharmaceutical dosage forms. Int J Pharma Bio Sci 2011;2:210-3.

15. E Shotton, K Ridgway. Physical Pharmaceutics. First Indian Edition; 2008. p. 326-8.

16. Napoleon. Pharmaceutical Titrimetric Analysis. First Edition; 2006. p. $4-44$.

\section{How to cite this article}

- $\quad$ Swathi P, S Vidyadhara, RLC Sasidhar, K Kalyan Chakravarthi. Method development and validation for the estimation of entecavir in bulk and pharmceutical dosage forms by RP-HPLC. Int J Curr Pharm Res 2017;9(5):107-111. 